\title{
Propofol lipidic infusion promotes resistance to antifungals by reducing drug input into the fungal cell Sofia Costa-de-Oliveira*1, Ricardo Araujo ${ }^{1}$, Ana Silva-Dias ${ }^{1}$, Cidália Pina- Vaz $^{1,2}$ and Acácio Gonçalves Rodrigues ${ }^{1,3}$
}

Address: ${ }^{1}$ Department of Microbiology, Faculty of Medicine, University of Porto, Porto, Portugal, ${ }^{2}$ Department of Microbiology, Hospital S. João, Porto, Portugal and ${ }^{3}$ Burn Unit, Department of Plastic and Reconstructive Surgery, Faculty of Medicine, University of Porto and Hospital S. João, Alameda Prof. Hernani Monteiro, 4200, Porto, Portugal

Email: Sofia Costa-de-Oliveira* - sqco@med.up.pt; Ricardo Araujo - ricjparaujo@yahoo.com; Ana Silva-Dias - i.dias.ana@gmail.com; Cidália Pina-Vaz - cpinavaz@yahoo.com; Acácio Gonçalves Rodrigues - agr@med.up.pt

* Corresponding author

Published: 17 January 2008

BMC Microbiology 2008, 8:9 doi:10.1 |86/|47|-2/80-8-9
Received: 20 July 2007

Accepted: 17 January 2008

This article is available from: http://www.biomedcentral.com/I47I-2180/8/9

(C) 2008 Costa-de-Oliveira et al; licensee BioMed Central Ltd.

This is an Open Access article distributed under the terms of the Creative Commons Attribution License (http://creativecommons.org/licenses/by/2.0), which permits unrestricted use, distribution, and reproduction in any medium, provided the original work is properly cited.

\begin{abstract}
Background: The administration of non-antifungal drugs during patient hospitalization might be responsible for discrepancies between in vitro and in vivo susceptibility to antifungals. Propofol is often administered to intensive care units as a sedative.
\end{abstract}

The purpose of this study was to evaluate the effect of propofol lipidic infusion upon the growth and susceptibility profile of pathogenic fungi.

Candida and Aspergillus were studied regarding the ability to grow and its susceptibility profile to antifungals in the presence of propofol infusion (Fresenius $\left.{ }^{\circledR}\right)\left(1.25,2.5\right.$ and $\left.5 \mathrm{mg}^{-\mathrm{ml}^{-1}}\right)$ and its lipidic vehicle. The intensity of fluorescence after staining with FUNI, in the presence and absence of propofol infusion, was determined by flow cytometry. Radioactivity assays were also performed in order to quantify the input of $\left[{ }^{3} \mathrm{H}\right]$ - itraconazole into the fungal cell in the presence of propofol. Assays were repeated after addition of sodium azide, in order to block efflux pumps.

Results: Propofol infusion promoted budding of Candida and the germination of Aspergillus, latter forming a lipid layer around the hypha. An increase of minimal fungicidal concentrations regarding both Candida and Aspergillus strains was found for all antifungals when incubated simultaneously with propofol infusion. A decrease of the intensity of fluorescence of Candida cells was systematically observed, as well as a significant reduced intracellular uptake of $\left[{ }^{3} \mathrm{H}\right]$ itraconazole in cells treated with propofol infusion, even after the blockade of efflux pumps. The results obtained when testing with the lipid vehicle were similar.

Conclusion: Propofol infusion, due to its lipidic vehicle, increased the fungal germination and promoted resistance to antifungals. This effect seems to be related to the reduced access and/or permeabilization to fungal cells by antifungals. 


\section{Background}

Discrepancies between in vivo and in vitro susceptibility to antifungals discourage microbiologists and clinicians regarding the routine use of susceptibility testing methods. Although in vitro resistance usually correlates with clinical resistance, high susceptibility in vitro is not always related to clinical success, particularly for Aspergillus spp., most strains being susceptible in vitro [1]. Ultimately, the mortality rates are unacceptably high in patients treated with antifungals that showed high in vitro efficacy $[1,2]$. Propofol is an intravenous hypnotic agent very popular for induction and maintenance of general and intravenous anaesthesia. It is commonly administered in Intensive Care Units to critically ill patients, often under mechanical ventilation, which represent a high risk group for health care related infections. The use of propofol has been previously associated to an increased risk for infection, although some controversy still remains $[3,4]$. It was proposed a low risk of contamination whenever providing standard hygienic precautions [3,5]. Nevertheless, other observations described the lipid emulsion of propofol as a good culture medium to support the growth of Candida albicans and Escherichia coli [6,7]. Additionally, other reports associated post surgical infections with the extrinsically contamination of propofol infusion $[5,8]$. Propofol has also been shown to inhibit a variety of functions of neutrophils in vitro, although such effect was not so evident in vivo [9].

We have studied the effect of the infusion of propofol and its lipidic vehicle upon antifungal susceptibility of Candida and Aspergillus spp. A promotion of resistance due to a decreased input of the antifungal drugs was found.

\section{Results}

In Candida strains, budding and germ tube formation were similar in presence of all tested concentrations of propofol infusion. In non-albicans strains, the incubation with $5 \mu \mathrm{g} . \mathrm{ml}^{-1}$ of propofol infusion resulted in a significant increased of cells with buds when comparing to control $(71.5 \% \pm 7.46$ versus $26.6 \% \pm 4.15$, C. parapsilosis $n=$ 5 as a representative example) $(p<0.001)$. Conversely, a significant reduction of germ tube formation was observed in $C$. albicans strains comparing with nontreated yeasts $(17.3 \% \pm 6.29$, versus $76.2 \% \pm 8.69, n=5)$ $(p<0.001)$. Aspergillus conidia germinated in RPMI 1640 culture medium after 4 to 6 hours, the hyphal form being obtained following 10 to 12 hours. Propofol infusion supported the germination of all Aspergillus strains, showing similar values to those obtained in plain RPMI 1640 medium. A significantly higher percentage of germination of A. fumigatus conidia was found in PBS plus propofol and plain propofol infusion in comparison with plain PBS $(21 \% \pm 3.6$ versus $6 \% \pm 1.6, n=5)(p=0.047)$ following 6 hours at $37^{\circ} \mathrm{C}$. Longer incubation periods of conidia with propofol infusion showed lipidic drops or a lipidic layer around the hypha, in all assays and with all strains, which remained present following several washings steps (Figure 1).

The result of MIC determination revealed that all fungal strains were susceptible to the tested antifungals. Propofol infusion or its vehicle, at the tested concentrations, consistently promoted an increase of MFC mean values for Candida and Aspergillus strains(Table 1), this effect being dose-dependent and statistically significant $(p<0.001)$; such effect was invariably observed with all strains of Candida and Aspergillus and with all antifungals, in some cases the mean values increasing over 4 fold. MFC values in the presence of $5 \mathrm{mg} \cdot \mathrm{ml}^{-1}$ of propofol infusion or its vehicle increased at least 2 dilutions in all strains (above the error rate of the method) for fluconazole and voriconazole, more than 3 dilutions for amphotericin B and 4 to 5 dilutions for posaconazole and itraconazole. There was no large variability between the tested strains.

Flow cytometry analysis of Candida blastoconidia resulted in $98 \%$ of cells stained with FUN1, even after the incubation of sodium azide (Figure $2 \mathrm{~b}$ ). However, after treatment with propofol infusion and stained with FUN1, a non-stained sub-population of cells, similar to autofluorescence, of around 15\% was revealed soon after $90 \mathrm{~min}$ utes (Figure 2c). This fact was unrelated with the incubation with sodium azide at a concentration able to block the efflux pumps (Figure 2c). The azole resistant strain of C. albicans 95-190 (with overexpression of efflux pumps genes), after treatment with propofol infusion and stained with FUN1, revealed a non-stained sub-population, similar to other susceptible strains, even after the blockade of the efflux pumps with sodium azide. This effect was similar in presence of all the tested concentrations of propofol.

After 1 hour, the accumulation of [ $\left.{ }^{3} \mathrm{H}\right]$-labelled itraconazole was detected in blastoconidia cells (control cells) (Figure 3). However, a decrease of 39\% in intracellular $\left[{ }^{3} \mathrm{H}\right]$-labelled itraconazole was seen when yeast cells were incubated with propofol lipid infusion (Figure 3). This effect was similar in presence of the different tested concentrations of propofol lipidic infusion and did not increase following the pre-incubation with sodium azide (Figure 3).

The results obtained in the different assays were similar when performed with propofol lipidic vehicle.

\section{Discussion}

Propofol administered in a lipid-based emulsion to patients has been shown to represent an excellent vehicle for supporting the growth of various microorganisms 

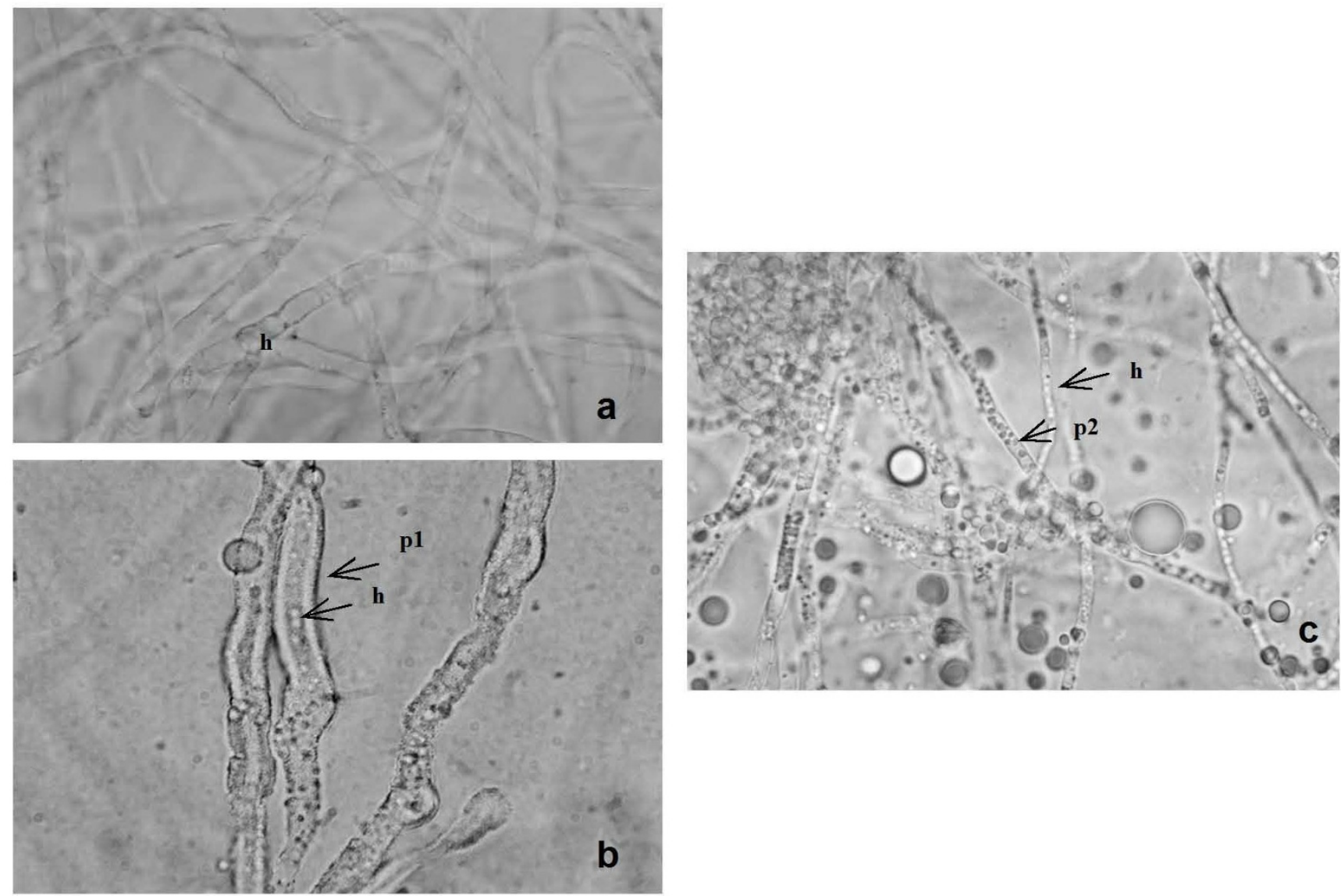

\section{Figure I}

Representative example of Aspergillus fumigatus, after 24 hours of incubation: a. non-treated cells; b. cells treated with 5 mg.mlI of propofol infusion; c. cells treated with $5 \mathrm{mg} \mathrm{ml}^{-1}$ of propofol infusion and washed thrice in sterilized water. (h hypha; $\mathbf{p} \mathbf{I}$ lipidic layer around hypha; $\mathbf{p 2}$ lipidic drops).

$[6,7]$. In the present study we clearly showed that budding of Candida spp. was promoted when incubated in the presence of propofol infusion, significantly more than in a culture medium. Aspergillus fumigatus germinate faster than the other Aspergillus species, possibly being associated to higher pathogenicity [10]. We showed that propofol infusion also supported mould germination and growth, apart from yeasts. It is important to emphasize that the propofol concentrations used in all assays are within the plasma levels often achieved in clinical practice $[11,12]$.

Due to the opacity of propofol infusion or its lipidic vehicle it was not possible to determine MIC values. As the conventional susceptibility phenotypes refer to MIC values, we could not establish the corresponding phenotypes after incubation with propofol. In the case of amphotericin B (a fungicidal drug to both Candida and Aspergillus) MFC, determined after culture in agar solid medium, usually corresponds to MIC values; for the other antifungals,
MFC values are usually located within one or three dilutions above the MIC. Some C. albicans and C. tropicalis showed trailing phenotype (about 2 dilutions) for azoles. This common effect may influence the evaluation of MFC values. However, trailing is only azole dependent and was not affected by the presence of propofol infusion. Nevertheless, we could observe a significant promotion of the MFC value in presence of propofol infusion, in some cases up to 4 dilutions, suggesting that the strains became quite tolerant to the effect of all antifungals. FUN1 is a fluorescent probe that is converted by metabolically active yeasts in intracytoplasmic vacuolar structures [13]. We have used this probe to study susceptibility of yeasts after incubation during one to two-hours with the antifungals; a higher intensity of fluorescent in susceptible strains, decreasing in resistant strains was described $[14,15]$. The decrease of the intensity of fluorescence could be explained by the presence of energy-dependent efflux pumps, which were reverted with sodium azide or several modulators $[13,14]$. In the present study, the viable cells showed a decrease of 
Table I: Minimal fungicidal concentration (MFC) values of Candidaand Aspergillus strains to AMB (amphotericin B), FLC (fluconazole), ITC (itraconazole), VRC (voriconazole) and PSC (posaconazole), determined by CLSI protocols, in the absence and presence of propofol infusion

Strains (n)

MFC values* range $\mu \mathrm{g} \cdot \mathrm{ml}^{-1}$

\begin{tabular}{|c|c|c|c|c|c|c|c|c|}
\hline Antifungals & Propofol(mg.ml-1) & C. albicans (5) & C. tropicalis (5) & C. parapsilosis (5) & C. glabrata (5) & A. fumigatus (5) & A. flavus (4) & A. niger (4) \\
\hline \multirow[t]{4}{*}{ AMB } & 0 & 0.25 & $0.25-1$ & $0.06-0.125$ & $0.25-0.5$ & $0.25-0.5$ & $0.5-1$ & $0.06-0.25$ \\
\hline & 1.25 & $0.5-1$ & I & 2 & 2 & $1-4$ & $1 \rightarrow>16$ & $0.25-1$ \\
\hline & 2.5 & $0.5-2$ & $1-2$ & 2 & 2 & $2-4$ & $1 \rightarrow>16$ & $0.25-1$ \\
\hline & 5 & $2-4$ & 2 & $2-8$ & $4-8$ & $4-16$ & $4->16$ & $0.5-2$ \\
\hline \multirow[t]{4}{*}{ FLC } & 0 & $8-16$ & $4-8$ & $8-16$ & 16 & nd & nd & nd \\
\hline & 1.25 & $16->64$ & $>64$ & $>64$ & $>64$ & nd & nd & nd \\
\hline & 2.5 & $16->64$ & $>64$ & $>64$ & $>64$ & nd & nd & nd \\
\hline & 5 & $16->64$ & $>64$ & $>64$ & $>64$ & nd & nd & nd \\
\hline \multirow[t]{4}{*}{ ITC } & 0 & nd & nd & nd & nd & $0.5-16$ & $0.125-0.25$ & $0.125-16$ \\
\hline & 1.25 & nd & nd & nd & nd & $>16$ & $2->16$ & $>16$ \\
\hline & 2.5 & nd & nd & nd & nd & $>16$ & $8->16$ & $>16$ \\
\hline & 5 & nd & nd & nd & nd & $>16$ & $16->16$ & $>16$ \\
\hline \multirow[t]{4}{*}{ VRC } & 0 & $0.06-0.25$ & $0.25-0.5$ & $0.5-1$ & $4-8$ & $0.25-4$ & $0.25-2$ & $0.06-8$ \\
\hline & 1.25 & $0.25->2$ & $>2$ & $>2$ & $>8$ & $2-8$ & $0.25-2$ & $1-16$ \\
\hline & 2.5 & $0.5->2$ & $>2$ & $>2$ & $>8$ & $2-8$ & $0.5-4$ & $1-16$ \\
\hline & 5 & $1->2$ & $>2$ & $>2$ & $>8$ & $2-8$ & $0.5-4$ & $1-16$ \\
\hline \multirow[t]{4}{*}{ PSC } & 0 & $0.06-0.125$ & $0.03-0.125$ & $0.06-0.125$ & $1-2$ & $0.03-0.25$ & $0.03-0.06$ & $0.06-1$ \\
\hline & 1.25 & I-2 & $>2$ & 2 & 2 & $1-4$ & $0.25-2$ & $0.125-8$ \\
\hline & 2.5 & $>2$ & $>2$ & 2 & $>2$ & $1-4$ & $0.5-2$ & $0.25-16$ \\
\hline & 5 & $>2$ & $>2$ & $>2$ & $>2$ & $1-4$ & $0.5-4$ & $0.25->16$ \\
\hline
\end{tabular}

nd not done

* The mean value for each strain was considered

the intensity of fluorescence in the presence of propofol which was not however reverted with sodium azide, even considering the resistant tested strain. Furthermore, cells were washed several times before the addition of the fluorescent probe in order to avoid its binding to propofol infusion. These results support that propofol infusion affected FUN1 access and/or permeabilization, reducing the input of the fluorescent probe into the cell. We had also previously shown that $\left[{ }^{3} \mathrm{H}\right]$-labelled itraconazole accumulation could be a useful tool to confirm the existence of efflux pumps in resistant Candida strains to azoles [16]. The blockade of efflux pumps with sodium azide resulted in the reduction of input of $\left[{ }^{3} \mathrm{H}\right]$-labelled itraconazole in Candida cells, after incubation with propofol infusion. In fact, propofol infusion was responsible for the difficult access of itraconazole to the fungal cell.

Attending to the facts that i) the increase of MFC values was similar with all antifungal drugs, including the recently available posaconazole; ii) FUN1 could not stain a considerable percentage of the yeast cells in presence of propofol infusion and iii) a lesser amount of $\left[{ }^{3} \mathrm{H}\right]-$ labelled itraconazole was present within such cells, even after the addition of sodium azide, we are forced to conclude that the promotion of antifungal resistance in presence of propofol lipidic infusion results from a reduced access and/or permeabilization of antifungal agents into the fungal cells. The same results were obtained when only the propofol vehicle was used, thus we had concluded that the major responsible for such effect was the lipidic nature of propofol infusion. The formation of a lipidic layer surrounding the cells supports such assumption, being responsible for the reduced permeabilization. Several studies reported that the lipidic membrane of fungal cells plays an important role in susceptibility to azoles $[17,18]$. Fluctuations in the lipidic environment affects, not only drug diffusion but also efflux pumps, coded specially by Cdr1 and Pdr5p, leading to multidrug azole 

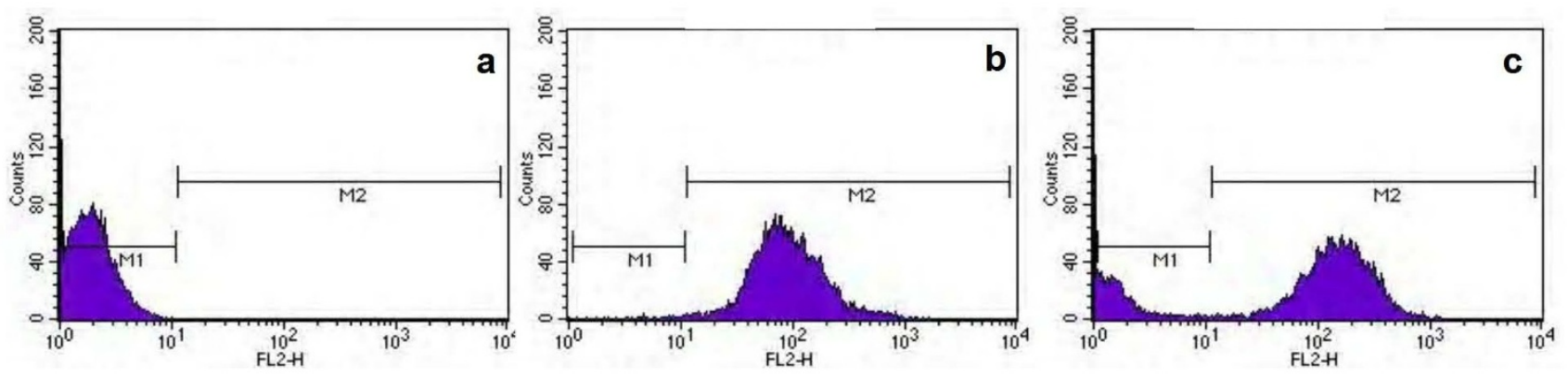

Figure 2

\section{Figure 2}

Flow cytometric histograms representing the emitted fluorescence after 90 minutes by: a. non-stained yeast cells (autofluorescence); b. cells treated with sodium azide and stained with FUNI; c. cells treated with sodium azide and 5 mg.ml-1 of propofol infusion and stained with FUNI (strain of Candida albicans shown as a representative example).

resistance $[19,20]$. In our study, as the efflux pumps were blocked with sodium azide, the increased MFC values probably resulted from poor diffusion of the antifungal drugs caused by the lipidic vehicle layer or drops deposited around the cells. The hypothesis that propofol could be binding the antifungal agent in culture medium reducing the free number of molecules available for penetrating the cells was also raised. MFC results were more evident when propofol was associated with itraconazole or posaconazole (increase of 4 to 5 dilutions), both lipophilic drugs. However, we must consider that different concen-

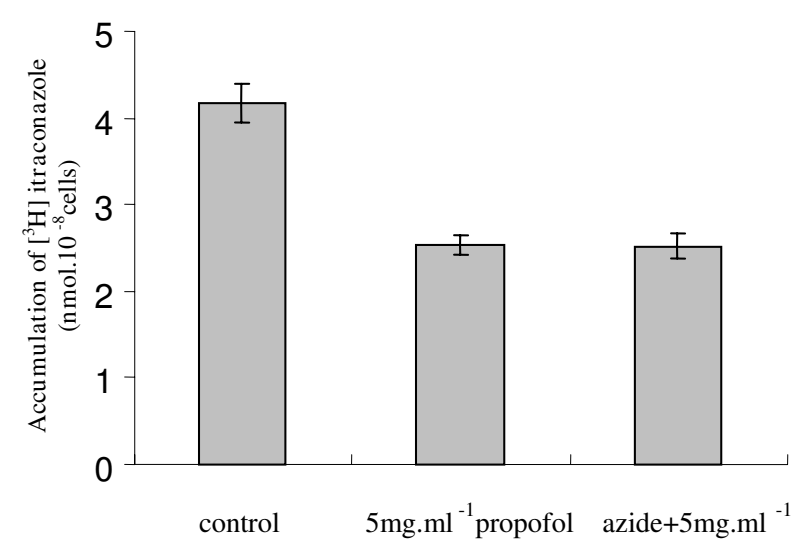

Figure 3

Effect of propofol up on [ $\left.{ }^{3} \mathrm{H}\right]$-labelled itraconazole accumulation in antifungal susceptible strain C. albicans ATCC 90028. The accumulation of itraconazole was measured in the absence and presence of $5 \mathrm{mg} \cdot \mathrm{ml}^{-1}$ of propofol and after a prior incubation with $0.1 \mathrm{mM}$ sodium azide. Dispersion bars relates to standard deviation. trations of propofol resulted in similar effects. The hypothesis that the lipidic vehicle of propofol might be playing a role in sterol homeostasis and changing the azole target, should be considered attending to other research [21]. Lipid uptake by the fungal cell was described in the presence of the azoles following longer incubation time (overnight) [21]. Measuring sterols in azole-treated fungi in the presence or not of the lipidic vehicle of propofol could be interesting however, the incubation time with propofol on cytometric and radioactivity studies was very short to allow the incorporation of the lipid in membrane.

\section{Conclusion}

The assays described in this manuscript provided an opportunity to describe the effect of propofol infusion in antifungal drug resistance. We concluded that propofol infusion, due to its lipidic vehicle reduced the access and/ or permeabilization to Candida and Aspergillus cells to main antifungals administered to patients.

The described effect should raise the alert to a promoted risk of fungal infections in patients receiving propofol infusions, resulting from the fact that fungal strains become increasingly resistant to antifungals.

\section{Methods \\ Strains}

Twenty clinical strains of Candida spp. (5 C. albicans, 5 C. tropicalis, 5 C. glabrata and 5 C. parapsilosis) and thirteen strains of Aspergillus spp.(5 A. fumigatus, 4 A. flavus and 4 A. niger) were studied. C. albicans 95-190, resistant to azoles by overexpression of efflux pumps genes (CDR1 and CDR2), was used during cytometric approach (strain 
kindly gift by Prof. Theodore White). Until testing, yeasts and moulds were kept frozen in Brain-Heart broth (Difco Laboratories, Detroit, MI, USA) with 5\% glycerol. For each experiment, the strains were subcultured twice on Sabouraud agar (Difco) at $35^{\circ} \mathrm{C}, 48$ hours for Candida and 7 days for Aspergillus.

\section{Drugs and Chemicals}

Propofol infusion Fresenius ${ }^{\circledast}$ (Kabi, France) at stock concentration of $1 \%$ was used. Propofol vehicle (soya bean oil, egg lecithin, glycerol, sodium hydroxide and sterile water) was also assayed. Fluconazole and voriconazole were obtained from Pfizer (Groton, CT, USA), amphotericin B from Bristol-Myers Squibb (New York, USA), itraconazole from Janssen-Cilag (Beerse, Belgium) and posaconazole from Shering-Plough (Kenilworth, NJ, USA). Antifungals drugs were maintained in stock solution at $-70^{\circ} \mathrm{C}$ until use. $\left[{ }^{3} \mathrm{H}\right]$-labelled itraconazole was supplied by Janssen-Cilag. Sodium azide was purchased from Sigma (Sigma-Aldrich, Germany).

\section{Growth assays}

After cultivation of Candida and Aspergillus strains in Sabouraud agar medium (Difco, Detroit, MI, USA), a $5 \times$ $10^{6} . \mathrm{ml}^{-1}$ blastoconidia or conidia suspension of Candida and Aspergillus was prepared in phosphate buffer saline (PBS) (Sigma) and $100 \mu \mathrm{l}$ were added in two parallel serial dilutions of propofol infusion (stock solution at $1 \%$ ) and its vehicle (both at $0,1.25,2.5$ and $5 \mathrm{mg} . \mathrm{ml}^{-1}$ final concentrations) in RPMI 1640 culture medium (Sigma), PBS and plain propofol infusion in a final volume of $500 \mu \mathrm{l}$. RPMI is a hydrophilic medium, however, solubility problems were not found. For Candida strains, samples were collected after 3 hours incubation at $37^{\circ} \mathrm{C}$, the cells were observed under phase contrast microscopy (Leitz Larborlux K) and the percentage of budding and germ tube formation (for C. albicans) were determined [22]. For Aspergillus, the percentage of conidial germination was determined after incubation for 6, 12 and 24 hours at $37^{\circ} \mathrm{C}[10]$.

\section{Susceptibility testing}

For Candida spp., the minimal inhibitory concentration (MIC) to fluconazole, voriconazole, posaconazole and amphotericin $\mathrm{B}$ (tested concentration range: 0.125-64 $\mu \mathrm{g} . \mathrm{ml}^{-1}, 0.03-16 \mu \mathrm{g} . \mathrm{ml}^{-1}, 0.03-16 \mu \mathrm{g} . \mathrm{ml}^{-1}$ and 0.03-16 $\mu \mathrm{g} . \mathrm{ml}^{-1}$, respectively) were determined accordingly the CLSI protocols M27-A2 (formerly NCCLS) [23]. Strains were classified as susceptible (S), susceptible-dose dependent (S-DD) and resistant (R) to fluconazole according to breakpoints defined by CLSI [23]. For voriconazole MICs $\leq 1 \mu \mathrm{g} \cdot \mathrm{ml}^{-1}$ were considered S, MIC $=2 \mu \mathrm{g} \cdot \mathrm{ml}^{-}$ ${ }^{1}$ considered S-DD and MIC $\geq 4 \mu \mathrm{g} \cdot \mathrm{ml}^{-1}$ considered R [24]. Although susceptibility breakpoints have not yet been established for amphotericin B and posaconazole, strains with MIC $\leq 1 \mu \mathrm{g} \cdot \mathrm{ml}^{-1}$ were considered susceptible $[25,26]$. Minimal fungicidal concentration (MFC) to all antifungals was also determined. The content of each well containing drug concentrations to and higher than the MIC, and also the positive growth control were transferred to Sabouraud dextrose agar plates and incubated at $35^{\circ} \mathrm{C}$ for $48 \mathrm{~h}$, as previously described [27]. The MFC was the lowest drug concentration that killed $\geq 99 \%$ of the final inoculum.

For Aspergillus spp., the CLSI protocol M 38-A was used to determine MIC values of voriconazole, posaconazole, itraconazole and amphotericin B (all antifungals tested concentration ranged 0.03-16 $\mu \mathrm{g} \cdot \mathrm{ml}^{-1}$ ) [28]. Although the unavailability of breakpoints for Aspergillus species, we followed several researchers that consider values of MIC $\leq$ $1 \mu \mathrm{g} \cdot \mathrm{ml}^{-1}$ as susceptible $[29,30]$. MFC values were determined, as previously described [31], and defined as the lowest drug concentration that showed either no growth or fewer than three colonies to obtain approximately 99 to 99.5\% killing activity.

The susceptibility tests to the antifungals mentioned above were repeated in the presence of the propofol infusion or its vehicle in three distinct concentrations (1.25, 2.5 and 5 mg.ml-1). Since propofol infusion and its vehicle are opaque solutions, making impossible MIC determination, the content of each well containing antifungal + propofol drugs was cultured for MFC determination and values compared with the MFC to antifungals alone.

\section{Flow cytometry analysis}

Yeast cells were incubated at $150 \mathrm{rpm}$, overnight, until late exponential growth, in Sabouraud broth (Difco) at $37^{\circ} \mathrm{C}$. Yeasts cells were harvested after centrifugation and a $1 \times$ $10^{6}$ cells. $\mathrm{ml}^{-1}$ suspension was prepared in PBS supplemented with $2 \%$ glucose (GH solution) and later divided into aliquots of $1 \mathrm{ml}$. The cells were then incubated with different concentrations of propofol infusion $(0,1.25,2.5$ and $5 \mathrm{mg} \cdot \mathrm{ml}^{-1}$ ) at $37^{\circ} \mathrm{C}$ for 90 minutes and afterwards washed thrice, ressuspended in sterile water supplemented with $2 \%$ glucose and stained with $0.5 \mu \mathrm{M}$ FUN1 (Molecular Probes, Europe BV, Leiden, Holland) for 30 minutes at $37^{\circ} \mathrm{C}$. A Beckman Coulter XL-MCL flow cytometer (Beckman-Coulter Corp., Hialeah, FL, USA) equipped with a $15 \mathrm{~nm}$ argon laser was used. From each suspension 30000-50000 cells were analysed. The intensity of fluorescence emitted by cells treated with propofol infusion was determined at FL2 (575 nm) and compared with non-treated cells (control). In parallel experiments, yeast cells were treated with $0.1 \mathrm{mM}$ sodium azide during 30 minutes, prior to incubation with propofol, as previously described [16], in order to block efflux pumps; thereafter, the same flow cytometry analytical protocol was used. 
Intracellular accumulation of $\left[{ }^{3} \mathrm{H}\right]$-labelled itraconazole Candida cells were initially incubated under similar conditions as previously described for flow cytometry assays. The cells were harvested by centrifugation at $5000 \mathrm{rpm}$ for 10 minutes at $4{ }^{\circ} \mathrm{C}$, washed thrice, ressuspended in PBS at a final concentration of $2.5 \times 10^{8}$ cells.ml-1 and incubated with $0,1.25$ and $5 \mathrm{mg} \cdot \mathrm{ml}^{-1}$ of propofol infusion at $37^{\circ} \mathrm{C}$, with continuous shaking at $300 \mathrm{rpm}$ for 30 minutes [16]. Parallel experiments were prepared, but also involving a pre-incubation of the yeasts cells with sodium azide at 0.1 $\mathrm{mM}$. The cells were washed thrice and $\left[{ }^{3} \mathrm{H}\right]$-labelled itraconazole was added to yeast suspensions at a final concentration of $3 \mu \mathrm{M}$, as previously described[16]; the cells were incubated in glass vials at $37^{\circ} \mathrm{C}$, with continuous shaking ( $300 \mathrm{rpm})$, during 1 hour and then harvested by centrifugation at $5000 \mathrm{rpm}$ for $10 \mathrm{~min}$ at $4^{\circ} \mathrm{C}$, washed thrice with $3 \mathrm{ml}$ of ice-cold PBS containing $10 \mu \mathrm{M}$ unlabelled itraconazole. The pellets were later ressuspended in $500 \mu \mathrm{l}$ of PBS and the radioactivity was determined, following the addition of a scintillation cocktail (Optiphase "Hiphase3", Perkin-Elmer), in a liquid scintillation counter (LKB Wallac, 1209 RackBeta).

\section{Lipidic vehicle experiments}

All the described experiments were repeated in the presence of the propofol lipidic vehicle used in Fresenius ${ }^{\circledR}$ formulation (soya bean oil, egg lecithin, glycerol, sodium hydroxide and sterile water).

\section{Statistical analysis}

The effects of different concentrations of propofol upon germination of fungal cells and MFC values of the distinct antifungals were compared using one-way analysis of variance (ANOVA) and Student's $t$-test. Significance was accepted at $p<0.05$. The SPSS 14.0 program for Windows was used to perform the statistical analysis. All susceptibility experiments were run in duplicate and growth and radioactivity assays in triplicate.

\section{Authors' contributions}

SCO and RA designed the study, performed the cytometric and radioactivity assays and wrote the manuscript. ASD performed growth and susceptibility assays. CPV and AGR also helped in the design of the study and draft the manuscript.

All authors read and approved the final manuscript.

\section{Acknowledgements}

The authors would like to thank Maria da Luz Dias, Mariana Castro Lopes and Teresa Deuchande for the excellent technical assistance.

This research was supported by the project POCTI/SAU-ESP/6 1080/2004.

\section{References}

I. Araujo R, Pina-Vaz C, Rodrigues AG: Susceptibility of environmental versus clinical strains of pathogenic Aspergillus. Int J Antimicrob Agents 2007, 29: 108-III.

2. White TC, Marr KA, Bowden RA: Clinical, cellular and molecular factors that contribute to antifungal resistance. Clin Microbiol Rev 1998, I I:382-402.

3. Bach A, Motsch J: Infectious risks associated with the use of propofol. Acta Anaesthesiol Scand 1996, 40:1 I89-1 I96.

4. Tallis J, Ryan GM, Lambert SB, Bowden DS, McCaw R, Birch CJ, Moloney M, Carnie JA, Locarnini SA, Rouch GJ, Catton MG: Evidence of patient-to-patient transmission of hepatitis $C$ virus through contaminated intravenous anaesthetic ampoules. J Virol Hepat 2003, 10:234-239.

5. McNeil MM, Lasker BA, Lott TJ, Jarvis WR: Postsurgical Candida albicans infections associated with an extrinsically contaminated intravenous anesthetic agent. J Clin Microbiol 1999, 37: 1398-1403.

6. Crowther J, Hrazdil J, Jolly D, Galbraith JC, Greacen M, Grace M: Growth of microorganisms in propofol, thiopental, and a $1: I$ mixture of propofol and thiopental. Anesth Analg 1996, 82:475-478.

7. Sosis M, Braverman B, Villaflor E: Propofol, but not thiopental, supports the growth of Candida albicans. Anesth Analg 1995, 8I:132-134.

8. Bennett SN, McNeil MM, Bland LA, Arduino MJ, Villarino E, Perrotta DM, Burwen DR, Welbel SF, Pegues DA, Stroud L, Zeitz PS, Jarvis WR: Postoperative infections traced to contamination of an intravenous anaesthetic, propofol. N Engl J Med 1995, 333:147-154

9. Frohlich D, Trabold B, Rothe G, Hoerauf K, Wittmann S: Inhibition of the neutrophil oxidative response by propofol: preserved in vivo function despite in vitro inhibition. Eur J Anaesthesiol 2006, 23:948-953.

10. Araujo R, Rodrigues AG: Variability of germinative potential among pathogenic species of Aspergillus. J Clin Microbiol 2004, 42:4335-4337.

II. Kazama T, Takeuchi K, Ikeda K, Ikeda T, Kikura M, lida T, Suzuki S, Hanai H, Sato S: Optimal propofol plasma concentration during upper gastrointestinal endoscopy in young, middle-aged, and elderly patients. Anesthesiol 2000, 93:662-669.

12. Takizawa D, Sato E, Nishikawa K, Hinohara H, Hiraoka H, Saito S, Goto F, Kunimoto F: Plasma concentration for optimal sedation and total body clearance of propofol in patients after esophagectomy. J Anesth 2005, 19:88-90.

13. Millard PJ, Roth BL, Thi H-PT, Yue ST, Haugland RP: Development of the FUNI family of fluorescent probes for vacuole labelling and viability testing of yeasts. Appl Environ Microbiol 1997, 63:2897-2905.

14. Pina-Vaz C, Sansonetty F, Rodrigues AG, Costa-Oliveira S, Tavares C, Martinez-de-Oliveira J: Cytometric approach for a rapid evaluation of susceptibility of Candida strains to antifungals. Clin Microbiol Infect 200I, 7:609-618.

15. Pina-Vaz C, Costa-de-Oliveira S, Rodrigues AG, Espinel-Ingroff A: Comparison of the two probes for testing susceptibilities of pathogenic yeasts to voriconazole, itraconazole and caspofungine by flow cytometry. J Clin Microbiol 2005, 43:4674-4679.

16. Pina-Vaz C, Rodrigues AG, Costa-de-Oliveira S, Ricardo E, Mardh P$A$ : Potent synergic effect between ibuprofen and azoles on Candida resulting from blockade of efflux pumps as determined by FUNI staining and flow cytomety. J Antimicrob Chemother 2005, 56:678-685.

17. Kohli A, Smriti A, Mukkopadhyay K, Rattan A, Prasad R: In vitro lowlevel resistance to azoles in Candida albicans is associated with changes in membrane lipid fluidity and asymmetry. Antimicrob Agents Chemother 2002, 46: 1046- 1052.

18. Loffler J, Einsele H, Hebart H, Schumacher U, Hrastnik C, Daum G: Phospolipid and sterol analysis of plasma membranes of azole-resistant Candida albicans strains. FEMS Microbiol Lett 2000, 185:59-63.

19. Mukhopadhyay K, Kohli A, Prasad R: Drug susceptibilities of yeasts cells are affected by membrane lipid composition. Antimicrob Agents Chemother 2002, 46:3695-3705.

20. Smriti A, Krishnamurthy S, Prasad R: Membrane fluidity affects functions of Cdrlp, a multidrug ABC transporter of Candida albicans. FEMS Microbiol Lett 1999, 173:475-478. 
21. Xiong Q, Hassan SA, Wilson WK, Han XY, May GS, Tarrand J], Matsuda SPT: Cholesterol Import by Aspergillus fumigatus and Its Influence on Antifungal Potency of Sterol Biosynthesis Inhibitors. Antimicrob Agents Chemother 2005, 49:5I8-524.

22. Rodrigues AG, Pina-Vaz C, Mardh PA, Martinez-de-Oliveira J, Freitasda-Fonseca $A$ : Inhibition of germ tube formation by Candida albicans by local anesthetics: an effect related to ionic channel blockade. Curr Microbiol 2000, 40: I 45- I 48.

23. Clinical Laboratory Standards Institute (CLSI): Reference method for broth dilution antifungal susceptibility testing of yeasts. 2nd edition. Approved standard M27-A2. CLSI, Wayne, PA, USA; 2002.

24. Pfaller MA, Diekema DJ, Rex JH, Espinel-Ingroff A, Johnson EM, Andes D, Chaturvedi V, Ghannoum MA, Odds FC, Rinaldi MG, Sheehan DJ, Troke P, Walsh TJ, Warnock DW: Correlation of MIC with outcome for Candida species tested against voriconazole: analysis and proposal for interpretive breakpoints. J Clin Microbiol 2006, 44:819-826.

25. Rex JH, Cooper CR, Merz WG Jr, Galgiani JN, Anaissie EJ: Detection of amphotericin B-resistant Candida isolates in a brothbased system. Antimicrob Agents Chemother 1995, 39:906-909.

26. Sabatelli F, Patel R, Mann PA, Mendrick CA, Norris CC, Hare R, Loebenberg D, Black TA, McNicholas PM: In vitro activities of Posaconazole, Fluconazole, Itraconazole, Voriconazole, and Amphotericin B against a large collection of clinically important molds and yeasts. Antimicrob Agents Chemother 2006, 50:2009-2015.

27. Cantón E, Pemán J, Viudes A, Quindós G, Gobernado M, EspinelIngroff A: Minimum fungicidal concentrations of amphotericin B for bloodstream Candida species. Diag Microbiol Infect Dis 2003, 45:203-206.

28. Clinical Laboratory Standards Institute (CLSI): Reference method for broth dilution antifungals susceptibility testing of conidium-forming filamentous fungi. M38-A. CLSI, Wayne, PA, USA; 2002.

29. Espinel-Ingroff $A$ : In vitro antifungal activities of anidulafungin and micafungin, licensed agents and the investigational triazole posaconazole as determined by NCCLS methods for 12,052 fungal isolates: review of the literature. Rev Iberoam Micol 2003, 20:121-136.

30. Chamilos G, Kontoyiannis DP: Update on antifungal drug resistance mechanisms of Aspergillus fumigatus. Drug Resist Updat 2005, 8:344-358.

31. Espinel-Ingroff A, Fothergill A, Peter J, Rinaldi MG, Walsh TJ: Testing Conditions for Determination of Minimum Fungicidal Concentrations of New and Established Antifungal Agents for Aspergillus spp.: NCCLS Collaborative Study. J Clin Microbiol 2002, 40:3204-3208.

Publish with Bio Med Central and every scientist can read your work free of charge

"BioMed Central will be the most significant development for disseminating the results of biomedical research in our lifetime. "

Sir Paul Nurse, Cancer Research UK

Your research papers will be:

- available free of charge to the entire biomedical community

- peer reviewed and published immediately upon acceptance

- cited in PubMed and archived on PubMed Central

- yours - you keep the copyright
BioMedcentral 